\begin{tabular}{|c|c|}
\hline & $\begin{array}{l}\text { International Journal of Trend in Scientific } \\
\text { Research and Development (IJTSRD) }\end{array}$ \\
\hline 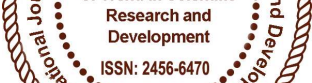 & International Open Access Journal \\
\hline 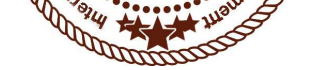 & ISSN No: 2456 - 6470 | www.ijtsrd.com | Volume - 2 | Issue - 2 \\
\hline
\end{tabular}

\title{
Analysing the Impact of Indian Disinvestment Policy on the Basis of Profitability : A Case of Selected Public Sector Units
}

\author{
Dr. Sudhendu Giri \\ Deputy Dean \& Professor-Finance, Maharshi Law School, \\ Maharshi Univeristy of Information and Technology, Noida, India
}

\begin{abstract}
As the Disinvestment took its final shape and implemented in the year 1991 formally by then Finance Minister Dr. Man Mohan Singh. The implication is yet to be tested about its successful implementation. Present paper is an attempt to test the Analytical Impact of Indian Disinvestment Policy on Selected Public Sector Undertakings(PSUs) in terms of Profitability, which is the sound indicator whether these undertakings outperformed or not. Several Indicators are used to test the Hypothesis which include Return on Sales Ratio, Return of Assets Ratio and Return on Capital Employed. Profitability Ratios are also computed after considering the Profit After Tax Basis. The final result shows a significance change in some trends in PSUs like ONGc and BHEL and others also got impacted by the Disinvestment drive.
\end{abstract}

Keywords: Disinvestment, Impact, PSUs, Profitability Ratio

\section{INTRODUCTION}

There is much ado about disinvestment policy and its result on the underlying entity since its formal announcement in 1991. It is great measure of concern for economist and others to evaluate the policy with regard to different parameters, It could be operational efficiency or be profitability measures to judge the Impact of Disinvestment Policy on PSUs. This paper is an attempt to test the profitability of selected PSUs in light of Return of Sales ratio, Return on Assets Ratio and Return of Capital Employed and Profitability Ratios which are calculated on before and after tax basis. The paper is divided into three parts, First Part shows the calculations based on Return on Sales ratio, Return on Assets ratio and Return on Capital Employed, T-value is calculated and different results are drawn and analyzed. In Part second some selected Profitability Ratios are calculated and analyzed on the basis of Profit After Tax. Pre and Post Disinvestment results are drawn and comparatively analyzed on the basis of T-value. In section III the consolidated impact of the Policy is analyzed with the help of Dividend Payout Ratio.

\section{Research Methodology and Hypothesis}

In this research paper we are applying the statistical hypothesis testing technique. We are trying to find out whether there is any significant change in the profitability pattern due to disinvestment, for this purpose samples collected are studied with the help of paired sample t-test at 5 percent significance level.

Part I Profitability Ratios calculated on The Basis Of Profit Before Depreciation, Interest And Taxes

\section{Ratios Calculated After Considering PBDIT}

We used following ratios in the section I, their calculation are done on the following basis:-
a. Return on Sales Ratio $=$ Profit Before Depreciation, Interest and Taxes/ Sales
b. Return on Capital Employed = Profit Before Depreciation Interest and Taxes / Capital
c. Return on Assets Ratio= Profit Before Depreciation Interest and Taxes / Assets


The following Hypothesis is designed for the purpose of testing the difference between pre disinvestment and post disinvestment ratios of profitability:-

Ho1:- RoS ratio between pre disinvestment period and post disinvestment period is not statistically different. $\mathrm{RoSa}=\mathrm{RoSb}$

H11: RoS ratio between pre disinvestment period and post disinvestment period is statistically different. $\mathrm{RoSa} \neq \mathrm{RoSb}$.

Ho2:- RoA ratio between pre disinvestment period and post disinvestment period is not statistically different. $\mathrm{RoAa}=\mathrm{RoAb}$.

H12:- RoA ratio between pre disinvestment period and post disinvestment period is statistically different. RoAa $\neq$ RoAb.

Ho3: RoCE between pre disinvestment period and post disinvestment period is not statistically different. $\mathrm{RoCEa}=\mathrm{RoCEb}$.
H13: RoCE between pre disinvestment period and post disinvestment period is statistically different. $\mathrm{RoCEa} \neq \mathrm{RoCEb}$.

The above hypothesis focuses on to test the extent of performance difference of PSUs on the basis of their pre disinvestment period and post disinvestment period. It is also tried to find out and identify the extent of difference. We used the symbols $\mathbf{a}$ and $\mathbf{b}$ for pre disinvestment period and post disinvestment period.

\section{1.a Analysis of Return on Sales Ratio(PBDIT/SALES)}

We computed the RoS ratio for the selected PSUs for both pre disinvestment period and post disinvestment period which is presented in Table 1. A comparative overview between pre disinvestment period and post disinvestment period is presented in Table as under:--

\section{International
of Tren Table:-1 \\ Return of Sales Ratio \\ (PBDIT/SALES)*100}

\begin{tabular}{|l|r|r|r|r|r|c|}
\hline & Mean(After) & Mean(Before) & Mean Diff. & T-Value & D.F. & $\begin{array}{l}\text { Sig.level } \\
\text { (2-Tailed) }\end{array}$ \\
\hline ONGC & $\mathbf{5 8 . 3 3 7 4 0 4}$ & $\mathbf{4 3 . 4 5 7 7 9 8}$ & $\mathbf{1 4 . 8 7 9 6 0 6}$ & $\mathbf{4 . 7 8 5}$ & $\mathbf{8}$ & $\mathbf{. 0 1 8}$ \\
\hline HPCL & 7.8336387 & 8.24309 & -0.4094513 & -0.381 & 8 & .876 \\
\hline BEL & 17.587297 & 20.1197468 & -2.5324498 & -1.783 & 8 & .168 \\
\hline CONCOR & 33.77965 & 38.06789 & -4.28824 & -0.839 & 6 & .639 \\
\hline IOCL & 7.9845606 & 7.7634193 & 0.2211413 & 0.238 & 8 & .245 \\
\hline MTNL & $\mathbf{4 6 . 8 3 7 9 8 2}$ & $\mathbf{5 8 . 4 5 1 3 9 6}$ & $\mathbf{- 1 1 . 6 1 3 4 1 4}$ & $\mathbf{- 3 . 1 7 4}$ & $\mathbf{8}$ & $\mathbf{. 0 0 5}$ \\
\hline BEML & $\mathbf{1 0 . 4 7 7 8 9 0 1}$ & $\mathbf{2 1 . 6 3 7 1 2 7 9}$ & $\mathbf{- 1 1 . 1 5 9 2 3 7 8}$ & $-\mathbf{7 . 8 3 3}$ & $\mathbf{8}$ & $\mathbf{. 0 0 2}$ \\
\hline BHEL & 16.908725 & 14.673819 & 2.234906 & 0.975 & 9 & .673 \\
\hline GAIL & 25.973122 & 32.208750 & -6.235628 & -0.563 & 8 & .564 \\
\hline BPCL & 7.7892778 & 8.8796552 & -1.0903774 & -1.0964 & 9 & .223 \\
\hline
\end{tabular}

Source: Compiled from the various issues of Public Enterprises Survey. 
Figure:1

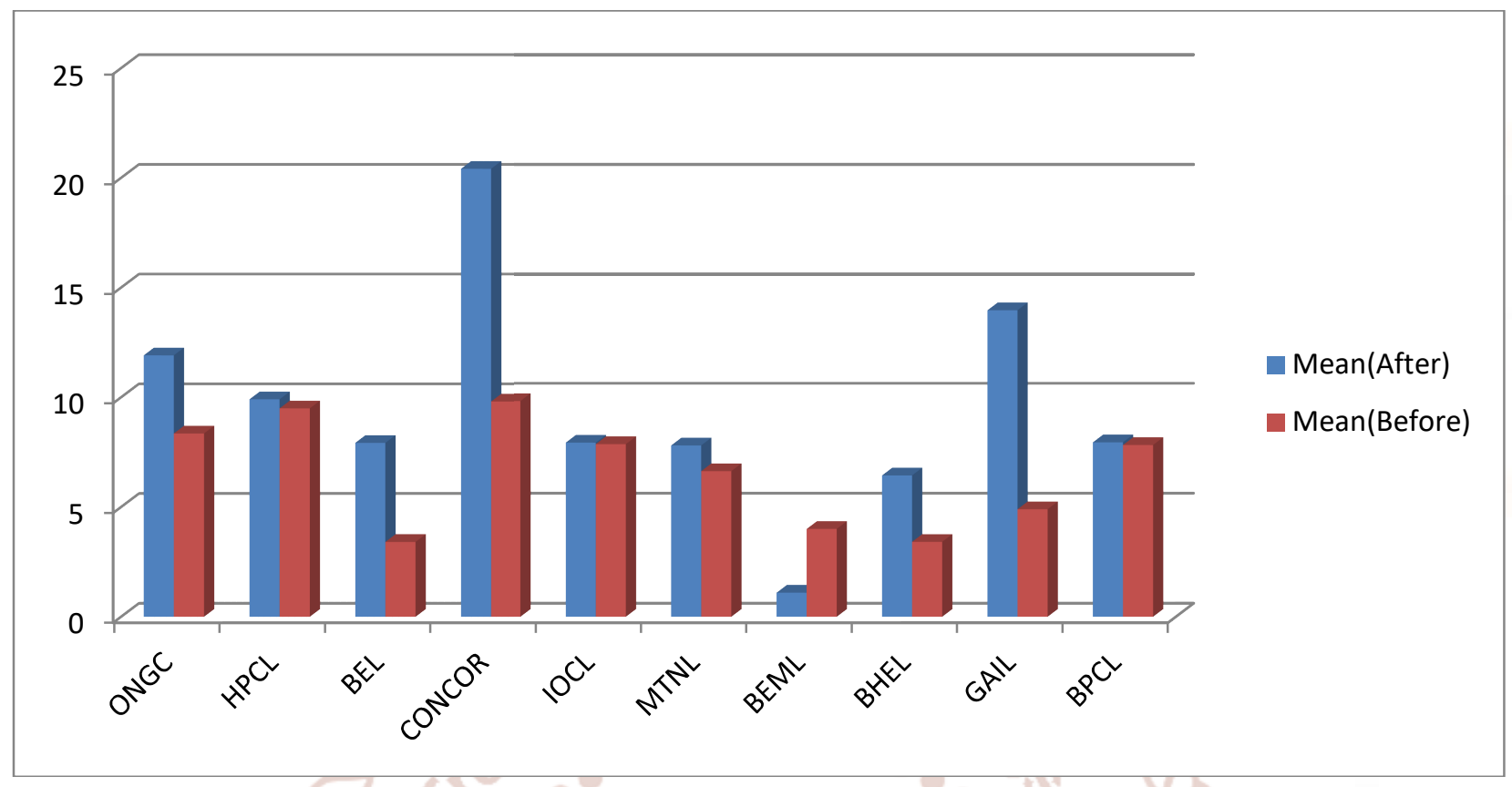

The difference between pre disinvestment period and post disinvestment period is evident from Table 1 . We computed the Return on Sales ratio for various Public Sector Undertakings (PSUs) by dividing PBDIT by SALES for both pre disinvestment period and post disinvestment period. It is clear from the Table 1 above that concerned ratio (RoS) reported an increasing trend only in the case of ONGC, IOCL and BHEL after the period of disinvestment but it is also clear from the above Table that other PSUs included in the study shown a better performance in terms of RoS ratio before disinvestment period. Hence, we are able to conclude that the major part of our study sample is not affected by the disinvestment policy and their performance is not improved with the inclusion of this policy. We computer the T-value for the purpose of finding out the difference on RoS ratio and its statistical significance for both pre disinvestment period and post disinvestment period. We can conclude from our finding that there is a significant difference for the PSUs like ONGC, MTNL IOCL and BEML but against it, all the other sample units the result is found as not statistically significant for RoS ratio for pre disinvestment period and post disinvestment period. If we do more analysis on the facts from Table 1 that it can be easily ascertained that ONGC shown favorable results after Disinvestment took place as its computed mean return after Disinvestment is in increasing trend. However, if we look at other PSUs like MTNL, BEML and GAIL we will be able to come to a conclusion that their mean returns for the pre disinvestment period were higher

than those of post disinvestment period and Disinvestment policy affected them negatively.

\section{1.b Analysis of Return on Assets Ratio(PBDIT/ASSETS)}

We calculated the value of Return on Assets ratio for both pre disinvestment period and post disinvestment period which is presented in Table 2 that clearly exhibits the results regarding difference between after and before disinvestment period. We used T-test to judge whether there is significant difference exist between the two periods or there is not any significant difference between the after and before disinvestment period. The ratio RoA is calculated by applying the formula Profit Before Depriciation, Interest and Taxes divided by Assets for both the said two periods.

Exhibits in Table 2 presents the complete picture of Pre and Post Disinvestment period on the basis of Return on Assets ratio. 
International Journal of Trend in Scientific Research and Development (IJTSRD) ISSN: 2456-6470

Table:2

Return on Asset Ratio

(PBDIT/ASSET)*100

\begin{tabular}{|l|r|r|r|r|r|c|}
\hline & Mean(After) & Mean(Before) & Mean Diff. & T-Value & \multicolumn{1}{l|}{ D.F. } & $\begin{array}{l}\text { Sig.level } \\
\text { (2-tailed) }\end{array}$ \\
\hline ONGC & $\mathbf{2 9 . 1 7 2 7 9 9}$ & $\mathbf{1 9 . 2 9 8 7 1 3}$ & $\mathbf{2 . 1 1 3 6 9 1}$ & $\mathbf{2 . 1 9 3}$ & $\mathbf{8}$ & $\mathbf{0 . 0 3 1}$ \\
\hline HPCL & $\mathbf{1 9 . 6 1 3 4 9 7}$ & $\mathbf{2 1 . 1 3 2 4 9 6}$ & $\mathbf{- 4 . 2 5 4 4 8 1}$ & $\mathbf{- 3 . 1 9 1}$ & $\mathbf{8}$ & $\mathbf{0 . 0 4 1}$ \\
\hline BEL & 13.276349 & 11.663951 & 11.846264 & 1.431 & 8 & 0.309 \\
\hline CONCOR & $\mathbf{3 3 . 9 7 7 3 9 4}$ & $\mathbf{1 7 . 8 9 3 7 6 1}$ & $\mathbf{- 2 8 . 7 8 1 4 6 6}$ & $\mathbf{7 . 2 9 3}$ & $\mathbf{6}$ & $\mathbf{0 . 0 0 2}$ \\
\hline IOCL & 15.976609 & 14.893129 & -19.402157 & 0.413 & 8 & 0.821 \\
\hline MTNL & 15.302293 & 17.498319 & 1.792673 & -1.281 & 8 & 0.311 \\
\hline BEML & $\mathbf{7 . 3 1 1 4 9 8}$ & $\mathbf{1 2 . 3 9 1 7 8 1}$ & $\mathbf{- 8 . 4 7 8 3 5 8}$ & $\mathbf{- 1 2 . 1 3 3}$ & $\mathbf{8}$ & $\mathbf{0 . 0 0 0}$ \\
\hline BHEL & 11.973419 & 10.383619 & -1.357306 & 0.935 & 9 & 0.399 \\
\hline GAIL & $\mathbf{2 2 . 3 3 5 3 9}$ & $\mathbf{1 3 . 9 8 3 4 0 1}$ & $\mathbf{3 5 . 3 5 1 3 7 4}$ & $\mathbf{5 . 1 3 9}$ & $\mathbf{8}$ & $\mathbf{0 . 0 0 1}$ \\
\hline BPCL & 16.189392 & 21.470083 & -7.847516 & -2.117 & 9 & 0.203 \\
\hline
\end{tabular}

Source: Compiled from the various issues of Public Enterprises Survey.

Figure:2

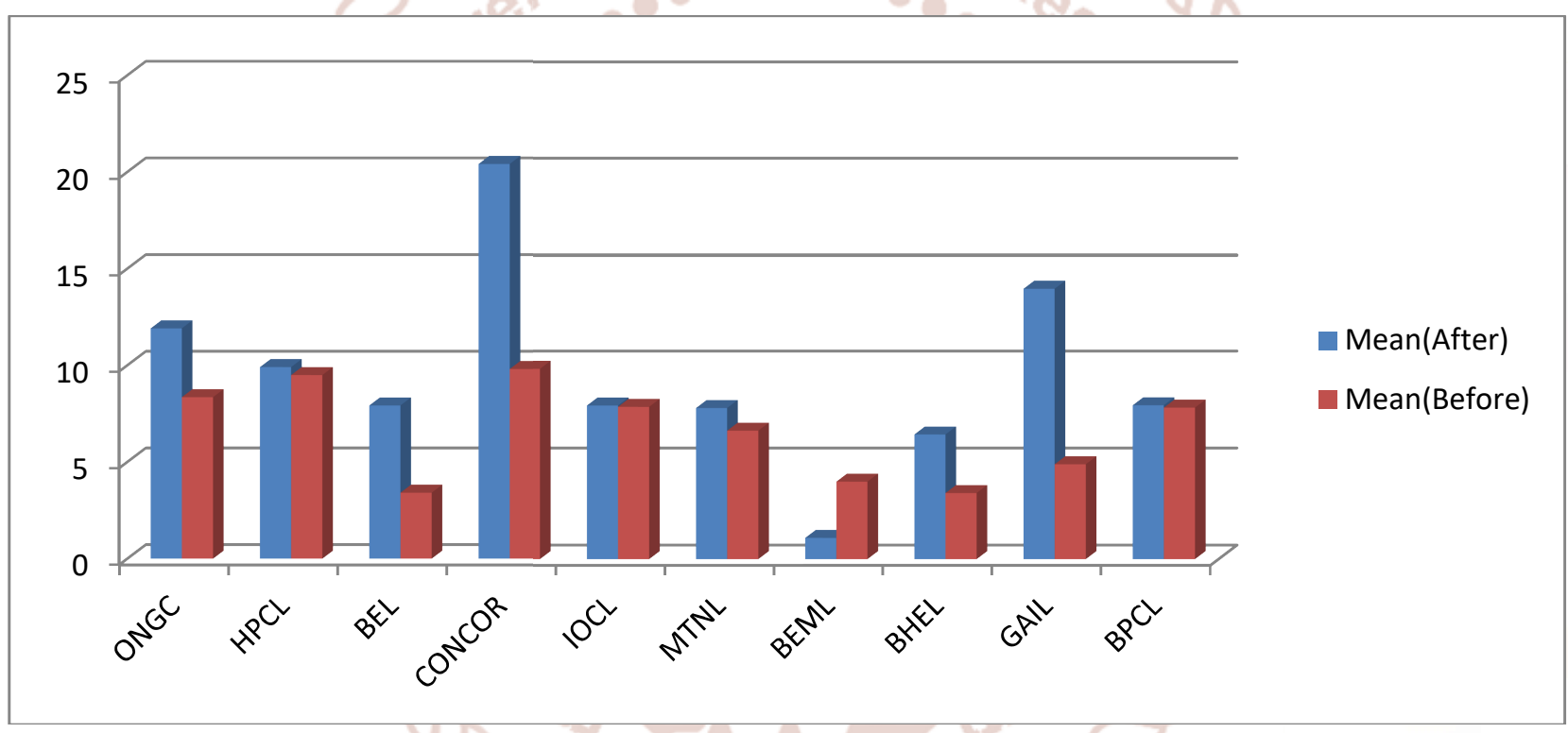

The values calculated for the two different periods exhibited in Table 2 shows the impact of Return on Assets ratio in terms of pre and post disinvestment period and it is made clear by the above table that firm performance in terms of RoA factor is reported better in ONGC, BEL, MTNL,IOCL,CONCOR and GAIL in post disinvestment period than pre disinvestment period. It can be ascertained that t-value at 5 percent significance level is said to exist in terms of ONGC, HPCL, CONCOR, BEML and GAIL and the null hypothesis for these PSUs is rejected. It can be concluded from the above table that the performance of some PSUs i.e. ONGC, BEL, CONCOR, IOCL, BHEL and GAIL looks better in post disinvestment period and they responded positively during post disinvestment. Specially the performance measure in terms of RoA ratio is found to be adverse in terms of BEML as it is statistically significance at 5 percent level of significance. Further to this PSUs HPCL, MTNL, BEML and BPCL showed a negative return on post disinvestment period but their performance in pre disinvestment period was good in comparison to post disinvestment period.

\section{1.c Return on Capital Employed(PBDIT/CAPITAL EMPLOYED)}

Calculation regarding RoCE are exhibited in Table 3 below for both pre and post disinvestment period. Proper analysis can be done through using the information which is presented in Table 3 for pre disinvestment and post disinvestment period. 
International Journal of Trend in Scientific Research and Development (IJTSRD) ISSN: 2456-6470

Table:3

Return on Asset Ratio

(PBDIT/ASSET)*100

\begin{tabular}{|l|r|r|r|r|r|c|}
\hline & Mean(After) & Mean(Before) & Mean Diff. & T-Value & \multicolumn{1}{l|}{ D.F. } & $\begin{array}{l}\text { Sig.level } \\
\text { (2-tailed) }\end{array}$ \\
\hline ONGC & 41.878123 & 39.764432 & 2.113691 & 1.293 & 8 & 0.329 \\
\hline HPCL & 38.983079 & 43.237560 & -4.254481 & -1.294 & 8 & 0.311 \\
\hline BEL & $\mathbf{4 5 . 2 3 7 6 0 9}$ & $\mathbf{3 3 . 3 9 1 3 4 5}$ & $\mathbf{1 1 . 8 4 6 2 6 4}$ & $\mathbf{4 . 9 3 6}$ & $\mathbf{8}$ & $\mathbf{0 . 0 0 6}$ \\
\hline CONCOR & 55.987639 & 84.769105 & -28.781466 & -0.951 & 6 & 0.396 \\
\hline IOCL & $\mathbf{3 5 . 7 9 6 8 3 3}$ & $\mathbf{5 5 . 1 9 8 9 9 0}$ & $\mathbf{- 1 9 . 4 0 2 1 5 7}$ & $\mathbf{- 3 . 2 7 3}$ & $\mathbf{8}$ & $\mathbf{0 . 0 2 9}$ \\
\hline MTNL & 21.976149 & 20.183476 & 1.792673 & 1.117 & 8 & 0.297 \\
\hline BEML & $\mathbf{1 1 . 4 7 9 0 3 3}$ & $\mathbf{1 9 . 9 5 7 3 9 1}$ & $\mathbf{- 8 . 4 7 8 3 5 8}$ & $\mathbf{- 6 . 1 9 3}$ & $\mathbf{8}$ & $\mathbf{0 . 0 0 0}$ \\
\hline BHEL & 30.743089 & 32.100395 & -1.357306 & 0.977 & 9 & 0.731 \\
\hline GAIL & 59.137905 & 23.786531 & 35.351374 & 3.117 & 8 & 0.061 \\
\hline BPCL & $\mathbf{4 3 . 9 8 3 4 6 7}$ & $\mathbf{5 1 . 8 3 0 9 8 3}$ & $\mathbf{- 7 . 8 4 7 5 1 6}$ & $\mathbf{- 3 . 9 5 7}$ & $\mathbf{9}$ & $\mathbf{0 . 0 2 1}$ \\
\hline
\end{tabular}

Source: Compiled from the various issues of Public Enterprises Survey.

Figure:3

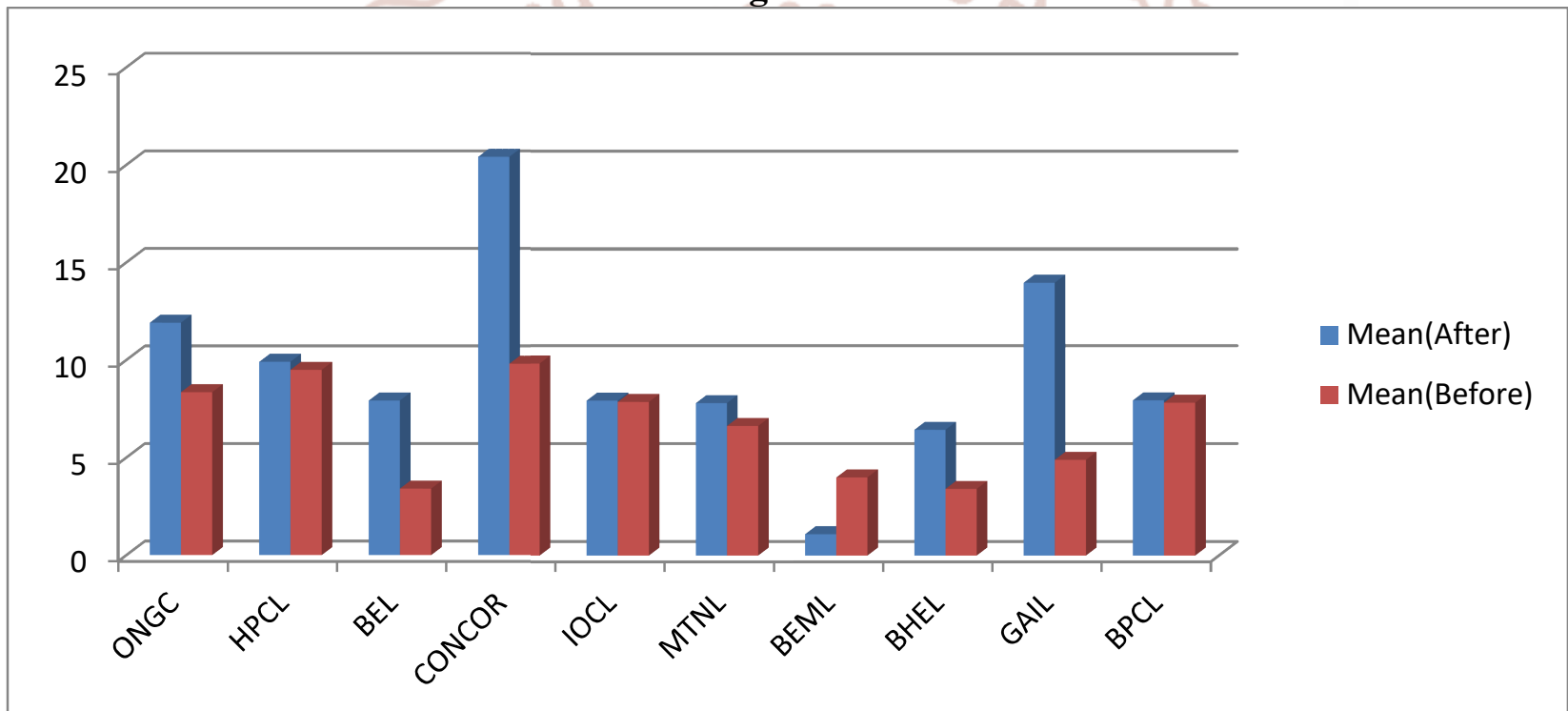

An analysis can be done from the above Table 3 in regard of Return on Capital Employed for the selected PSUs in our study. The said ratio is calculated by dividing Profit Before Depriciation, Interest and Taxes by Capital Employed. We can conclude from the above table that the performance of some PSUs improved in post disinvestment period like ONGC, BEL, MTNL and GAIL. But the contrary results are drawn from the analysis of HPCL, CONCOR,IOCL,BEML and BPCL as their performance measured in terms of mean return declined in post disinvestment period in comparison to pre disinvestment period. The null hypothesis is rejected in cases of BEL, IOCL,BEML and BPCL as the significant difference is reported at 5 percent level of significance. In general, we can conclude that four units performed well in post disinvestment period and six units done well in pre disinvestment period.

\section{Part II Profitability Ratios Calculated On The Basis Of Profit After Tax}

In part II we considered Profit After Tax(PAT) for calculation of profitability ratios for the Public Sector Units under consideration. The following ratios are calculated adopting the following formula:-

\section{Ratios Calculated After Considering PAT}

The ratios considered in this section are calculated on the basis of following formula:-
a. Return of Sales Ratio $=$
Profit After Tax/ Sales
b. Return on Capital Employed =
Profit After Tax/ Capital Employed
c. Return on Assets Ratio
Profit After Tax / Assets 
International Journal of Trend in Scientific Research and Development (IJTSRD) ISSN: 2456-6470

The following hypothesis is designed to test the designed results and effects thereon:-

H0 1 RoS Ratio between pre and post disinvestment period is not statistically different.

RoSa $=$ RoSb.

H1 1 RoS Ratio between pre and post disinvestment period is statistically different.

RoSa $\neq$ RoSb.

H0 2 RoA Ratio between pre and post disinvestment period is not statistically different.. RoA $\mathbf{a}=\operatorname{RoAb}$

H1 2 RoA Ratio between pre and post disinvestment period is statistically different.

RoAa $\neq$ RoAb.

H0 3 RoCE between pre and post disinvestment period is not statistically different.

RoCEa $=$ RoCEb

H1 3 RoCE between pre and post disinvestment period is statistically different.

RoCEa $\neq$ RoCEb

\section{2.a Return on Sales Ratio (PAT/Sales)}

Comparative view of performance on the basis of said measure for pre and post disinvestment period is shown below in Table 4:-

\section{Table:4}

Return on Sales Ratio

(PAT/Sales)*100

\begin{tabular}{|l|r|r|r|r|r|r|}
\hline & Mean(After) & Mean(Before) & Mean Diff. & \multicolumn{1}{l|}{ T-Value } & D.F. & \multicolumn{1}{l|}{$\begin{array}{l}\text { Sig.level } \\
(2 \text {-tailed) }\end{array}$} \\
\hline ONGC & 22.331347 & 18.973481 & 3.357866 & 1.103 & 8 & 0.239 \\
\hline HPCL & 4.919831 & 3.935161 & 0.98467 & 8 & 0.273 \\
\hline BEL & 8.119038 & 5.910381 & 2.208657 & 1.603 & 8 & 0.235 \\
\hline CONCOR & 19.881304 & 22.900139 & -3.018835 & -0.169 & 6 & 0.893 \\
\hline IOCL & 4.927831 & 4.823143 & 0.104688 & -0.393 & 8 & 0.438 \\
\hline MTNL & 22.912737 & 19.873141 & 3.039596 & 2.103 & 8 & 0.193 \\
\hline BEML & $\mathbf{1 . 0 8 7 9 3 1}$ & $\mathbf{6 . 9 7 1 3 4 1}$ & $\mathbf{- 5 . 8 8 3 4 1}$ & $\mathbf{- 7 . 0 1 3}$ & $\mathbf{8}$ & $\mathbf{0 . 0 0 1}$ \\
\hline BHEL & $\mathbf{9 . 8 7 6 9 3 1}$ & $\mathbf{5 . 9 8 6 9 8 3}$ & $\mathbf{3 . 8 8 9 9 4 8}$ & $\mathbf{6 . 1 9 3}$ & $\mathbf{9}$ & $\mathbf{0 . 0 0 3}$ \\
\hline GAIL & 15.798139 & -17.497131 & 33.29527 & 1.306 & 8 & 0.301 \\
\hline BPCL & 3.398149 & 3.219183 & 0.178966 & 0.431 & 9 & 0.483 \\
\hline
\end{tabular}

Source: Compiled from the various issues of Public Enterprises Survey.

Figure:4

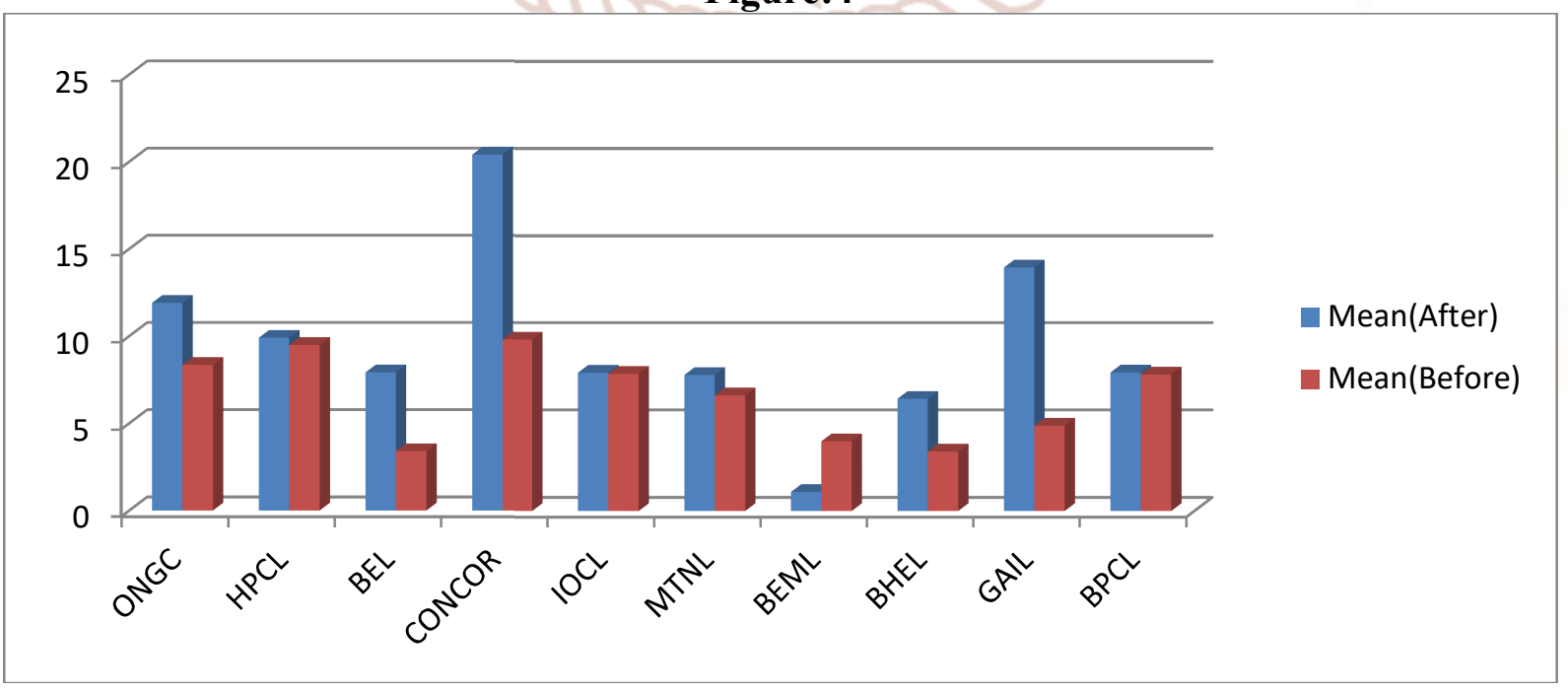


From the exhibits of Table 4 we can conclude the differences for pre and post differences period for Public Sector Units under consideration at 5\% level of significance after considering the Return on Sales ratio. After analyzing the Table 4 we can conclude that the ratio under consideration showed increasing trend in case of BHEL, on the other hand same ratio is found in decreasing trend in case of BEML. The above table shows the significant difference in these PSUs i.e. BHEL and BEML and Null Hypothesis is said to be rejected for these cases. By analyzing we can also conclude about a positive trend in case of ONGC,HPCL,BEL,IOCC,MTNL and BHEL while CONCOR,BEML and GAIL reported negative pattern against the same measure of calculation. After comparing the results comparing the Return on Sales ratio for pre and post disinvestment period for sample data indicates that the peroformance of ONGC,HPCL,BEL,MTNL,BHEL and GAIL improved after disinvestment while on the other hand the performance of CONCOR and BEML deteriorated more after disinvestment. As we can also say that the Null Hypothesis for these cases rejected as T-value shows the significant difference in case of BHEL and BEML.

\section{2.b Return on Assets(PAT/ASSETS)}

In the second subsection of Part II we considered the RoA ratio which is calculated on the basis of Profit After Tax divided by Assets for pre and post disinvestment period. Table 5 below picturises a comparative performance view for pre and post disinvestment period. A quick analysis can be done by having a comparative look at the Table given below:-

Table:5

Return on Asset Rato

(PAT/ASSETS)*100

\begin{tabular}{|c|c|c|c|c|c|c|}
\hline & Mean(After) & Mean(Before) & Mean Diff. & T-Value & D.F & $\begin{array}{l}\text { Sig.level } \\
\text { (2-tailed) }\end{array}$ \\
\hline ONGC & 11.915381 & 8.356071 & O $\quad 3.55931$ & nth 1.316 & 8 & 0.183 \\
\hline HPCL & 9.913493 & 9.500318 & 0.413175 & 0.431 & 8 & 0.619 \\
\hline BEL & 7.928371 & 3.413851 & 4.51452 & 3.613 & 8 & 0.023 \\
\hline CONCOR & 20.418735 & 9.814718 & 10.604017 & 6.037 & 6 & 0.001 \\
\hline IOCL & 7.921835 & 7.853511 & 0.068324 & 0.193 & 8 & 0.673 \\
\hline MTNL & 7.795313 & 6.625673 & 1.16964 & 2.103 & 28 & 0.307 \\
\hline BEML & $\mathbf{1 . 0 9 7 7 3 5}$ & 3.998536 & -2.900801 & -5.847 & 8 & 0.002 \\
\hline BHEL & 6.431293 & $\mathbf{3 . 4 1 1 0 1 3}$ & 3.02028 & $\mathbf{5 . 3 0 1}$ & 9 & 0.002 \\
\hline GAIL & 13.943615 & 4.893513 & 9.050102 & 5.003 & 8 & 0.000 \\
\hline BPCL & 7.936673 & 7.813651 & 0.123022 & $\begin{array}{r}1.035 \\
\end{array}$ & P & 0.317 \\
\hline
\end{tabular}

Source: Compiled from the various issues of Public Enterprises Survey.

Figure:5

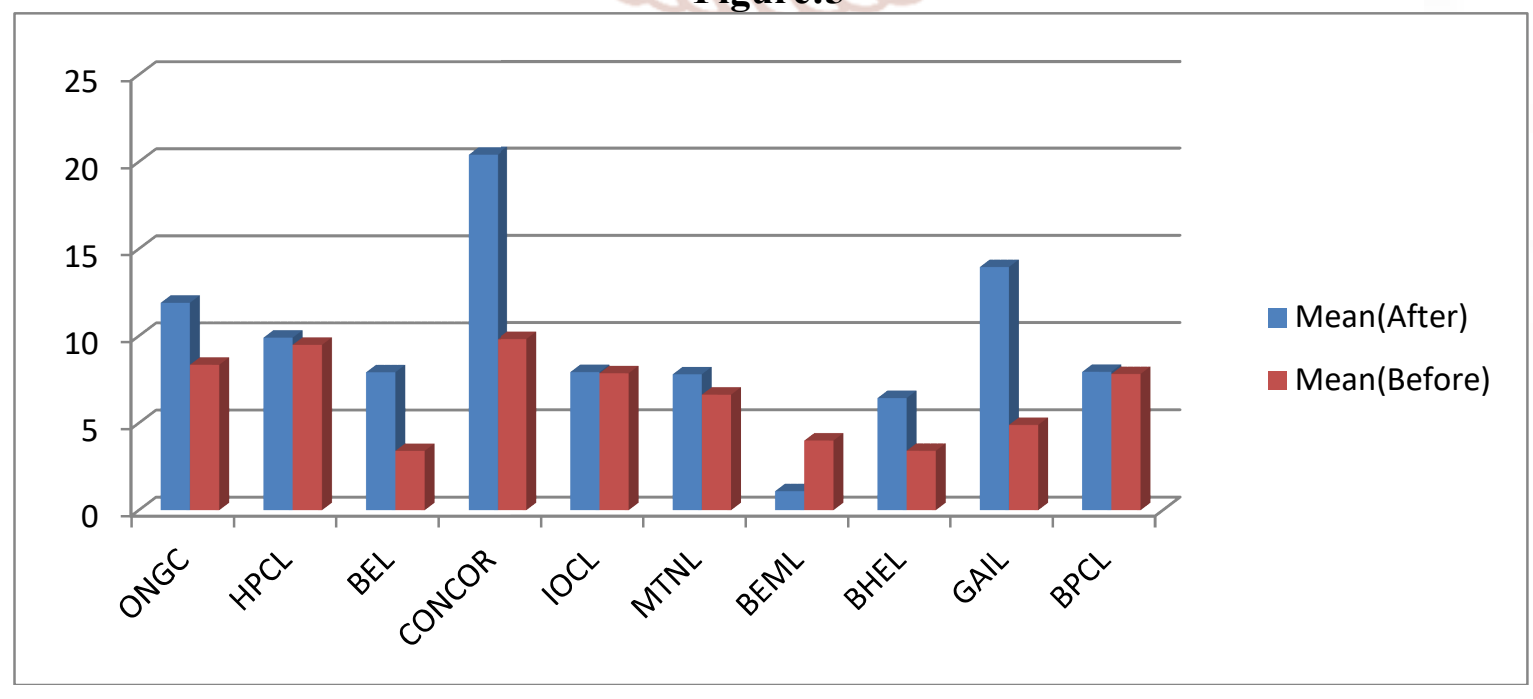


We can analyze the data given in Table 5 and come to a comparative presentation for pre and post disinvestment period. It can be concluded that results in terms of Return on Assets ratio reports significant difference in case of BEL,CONCOR,BEML,BHEL and GAIL for pre and post disinvestment period and therefore Null Hypothesis is said to be rejected for these cases at 5\% significant level. We can further conclude by analyzing a positive performance trend in case of ONGC,HPCL,BEL,CONCOR,MTNL,BHEL and GAIL in post disinvestment period but their difference between pre and post disinvestment period is not found statistically significant. Further, it is clear from the Table 5 that CONCOR and GAIL reported very high Return on Asset ratio after disinvestment. BEML is the only PSU in our study who showed negative performance after disinvestment. Finally, it can be concluded that nine out of ten PSUs under the present study shown a positive performance pattern after disinvestment and their performance improved in terms of RoA ratio. Therefore, it can be said that Disinvestment brings positive impact in terms of RoA for selected PSUs in our study.

\section{2.c Return on Capital Employed(PAT/CAPITAL EMPLOYED)}

Calculation regarding RoCE after considering Profit After Tax are exhibited in Table 6 below for both pre and post disinvestment period. Proper analysis can be done through using the information which is presented in Table 6 for pre disinvestment and post disinvestment period.

\section{Table:6}

Return on Capital Employed (PAT/CAPITAL EMPLOYED)*100

\begin{tabular}{|l|l|l|l|r|r|r|}
\hline & Mean(After) & Mean(Before) & Mean Diff. & \multicolumn{1}{l|}{ T-Value } & \multicolumn{1}{l|}{ D.F. } & \multicolumn{1}{l|}{$\begin{array}{l}\text { Sig.level } \\
(2 \text {-tailed })\end{array}$} \\
\hline ONGC & 19.354019 & 16.693413 & 2.660606 & 0.349 & 8 & 0.612 \\
\hline HPCL & 20.345041 & 17.837139 & 2.507902 & 1.019 & 8 & 0.401 \\
\hline BEL & $\mathbf{1 9 . 3 9 6 8 2 5}$ & $\mathbf{9 . 3 5 9 7 3 1}$ & $\mathbf{1 0 . 0 3 7 0 9 4}$ & $\mathbf{2 . 9 8 7}$ & $\mathbf{8}$ & $\mathbf{0 . 0 0 4}$ \\
\hline CONCOR & 31.839537 & 51.600792 & -19.761255 & 0.983 & $\mathbf{6}$ & 0.517 \\
\hline IOCL & 16.702963 & 25.632987 & -8.930024 & -3.183 & 8 & 0.071 \\
\hline MTNL & $\mathbf{1 3 . 3 9 2 7 8 1}$ & $\mathbf{8 . 2 9 8 0 0 1}$ & $\mathbf{5 . 0 9 4 7 8}$ & $\mathbf{3 . 8 5 9}$ & $\mathbf{8}$ & $\mathbf{0 . 0 3 1}$ \\
\hline BEML & $\mathbf{2 . 6 9 7 4 8 9}$ & $\mathbf{6 . 3 9 7 3 3 1}$ & $\mathbf{- 3 . 6 9 9 8 4 2}$ & $\mathbf{- 2 . 9 1 8}$ & $\mathbf{8}$ & $\mathbf{0 . 0 2 1}$ \\
\hline BHEL & $\mathbf{1 5 . 8 7 6 3 8 1}$ & $\mathbf{8 . 9 3 1 2 8 2}$ & $\mathbf{6 . 9 4 5 0 9 9}$ & $\mathbf{4 . 9 8 3}$ & $\mathbf{9}$ & $\mathbf{0 . 0 0 1}$ \\
\hline GAIL & $\mathbf{3 3 . 6 3 3 8 1 5}$ & $\mathbf{6 . 9 7 3 3 1 7}$ & $\mathbf{2 6 . 6 6 0 4 9 8}$ & $\mathbf{3 . 0 8 3}$ & $\mathbf{8}$ & $\mathbf{0 . 0 2 3}$ \\
\hline BPCL & 19.766983 & 20.004831 & -0.237848 & -0.281 & 9 & 0.137 \\
\hline
\end{tabular}

Source: Compiled from the various issues of Public Enterprises Survey.

Figure:6

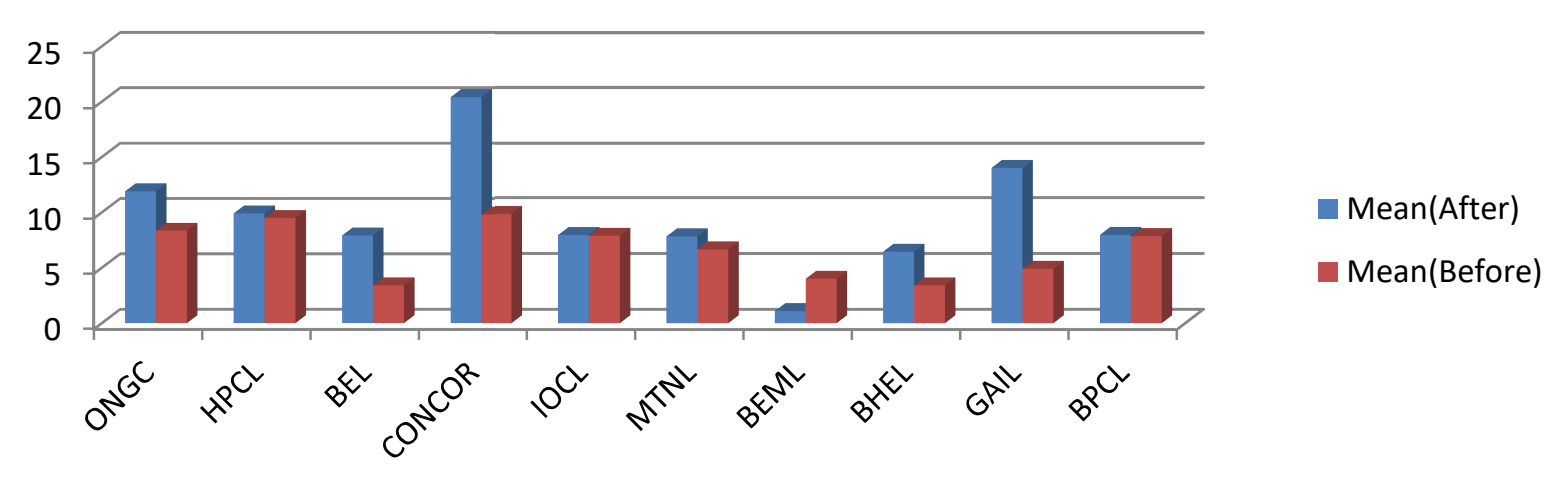

An analysis over impact of Disinvestment considering Return on Capital employed over selected units can be done through Table 6 . For this purpose we applied two pair sample T-test at five percent level of significance. It can be concluded with the help of above Table that some selected PSUs like BEL,MTNL,BEML,BHEL and GAIL shows significant differences in their results regarding pre and post disinvestment period and the reason being Null Hypothesis is said to be rejected for these cases at 5\% level of significance. We can further our 
analysis by explaining the positive performance trend shown by ONGC, HPCL,BEL,MTNL,BHEL and GAIL, while on the contrary PSUs in our study that performed adversely due to disinvestment includes CONCOR,IOCL,BEML and BPCL. Overall, it can be concluded that six units out of ten performed well in post disinvestment period while rest four units could not take the disinvestment and performed negatively.

\section{PART III CONSOLIDATED VIEW OF DISINVESTMENT}

The true reflection of the market value of shares of any firm is the combined outcome of its profitability and its dividend policy, which has significance for one another. If firm is profitable then only it can distribute dividends and retain a portion which again yields return if invested rationally @Return on Equity(RoE). Thus it became pertinent to study the consolidated effect of this particular measure, used here as PayOut Ratio and its consolidated impact of disinvestment. The following para is dedicated to the calculation and analysis of consolidated impact of Disinvestment in terms of Pay Out Ratio.

\section{3.a Dividend PayOut Ratio(PAT/Dividend)}

Calculation and subsequent analysis of Dividend PayOut Ratio for pre and post disinvestment period is presented below in Table 7:-

Table:7

\section{Dividend PayOut Ratio \\ PAT/DIVIDEND}

\begin{tabular}{|l|r|r|r|r|r|r|}
\hline & Mean(After) & Mean(Before) & Mean Diff. & \multicolumn{1}{l|}{ T-Value } & \multicolumn{1}{l}{ D.F. } & \multicolumn{1}{l|}{$\begin{array}{l}\text { Sig.level } \\
\text { (2-tailed) }\end{array}$} \\
\hline ONGC & $\mathbf{0 . 3 7 8 4 7 1 9}$ & $\mathbf{0 . 0 9 3 8 7 6}$ & $\mathbf{0 . 2 8 4 5 9 5 9}$ & $\mathbf{5 . 4 1 9}$ & $\mathbf{8}$ & $\mathbf{0 . 0 0 1}$ \\
\hline HPCL & $\mathbf{0 . 4 9 3 8 7 6 3}$ & $\mathbf{0 . 1 2 3 8 3 3}$ & $\mathbf{0 . 3 7 0 0 4 3 3}$ & $\mathbf{5 . 1 0 7}$ & $\mathbf{8}$ & $\mathbf{0 . 0 0 1}$ \\
\hline BEL & 0.4346209 & 0.5130817 & 0.0784608 & -2.193 & 8 & 0.197 \\
\hline CONCOR & $\mathbf{0 . 2 1 3 5 7 7 1}$ & $\mathbf{0 . 0 9 8 3 7 1 2}$ & $\mathbf{0 . 1 1 5 2 0 5 9}$ & $\mathbf{7 . 2 1 8}$ & $\mathbf{8}$ & $\mathbf{0 , 0 0 5}$ \\
\hline IOCL & $\mathbf{0 . 3 1 3 9 7 3 5}$ & $\mathbf{0 . 0 7 8 3 9 1 3}$ & $\mathbf{0 . 2 3 5 5 8 2 2}$ & $\mathbf{7 . 3 1 1}$ & $\mathbf{8}$ & $\mathbf{0 . 0 0 0}$ \\
\hline MTNL & 0.2147817 & 0.3713491 & 0.1565675 & -0.813 & 6 & 0.513 \\
\hline BEML & $\mathbf{0 . 5 1 3 7 7 2 9}$ & $\mathbf{0 . 2 9 3 7 2 5 1}$ & $\mathbf{0 . 2 2 0 0 4 7 8}$ & $\mathbf{4 . 2 1 5}$ & $\mathbf{8}$ & $\mathbf{0 . 0 1 0}$ \\
\hline BHEL & $\mathbf{0 . 2 6 3 9 8 1 9}$ & $\mathbf{0 . 4 1 9 8 6 1}$ & $\mathbf{0 . 1 5 5 8 7 9 1}$ & $\mathbf{- 3 . 1 6 3}$ & $\mathbf{7}$ & $\mathbf{0 . 0 2 9}$ \\
\hline GAIL & $\mathbf{0 . 3 8 5 7 4 8 5}$ & $\mathbf{0 . 1 0 8 3 5 9 7}$ & $\mathbf{0 . 2 7 7 3 8 8 8}$ & $\mathbf{1 7 . 4 2 3}$ & $\mathbf{8}$ & $\mathbf{0 . 0 0 0}$ \\
\hline BPCL & $\mathbf{0 . 3 6 5 6 8 9 1}$ & $\mathbf{0 . 1 0 1 7 2 8 1}$ & $\mathbf{0 . 2 6 3 9 6 1}$ & $\mathbf{6 . 1 3 9}$ & $\mathbf{7}$ & $\mathbf{0 . 0 0 1}$ \\
\hline
\end{tabular}

Source: Compiled from the various issues of Public Enterprises Survey.

Figure:7

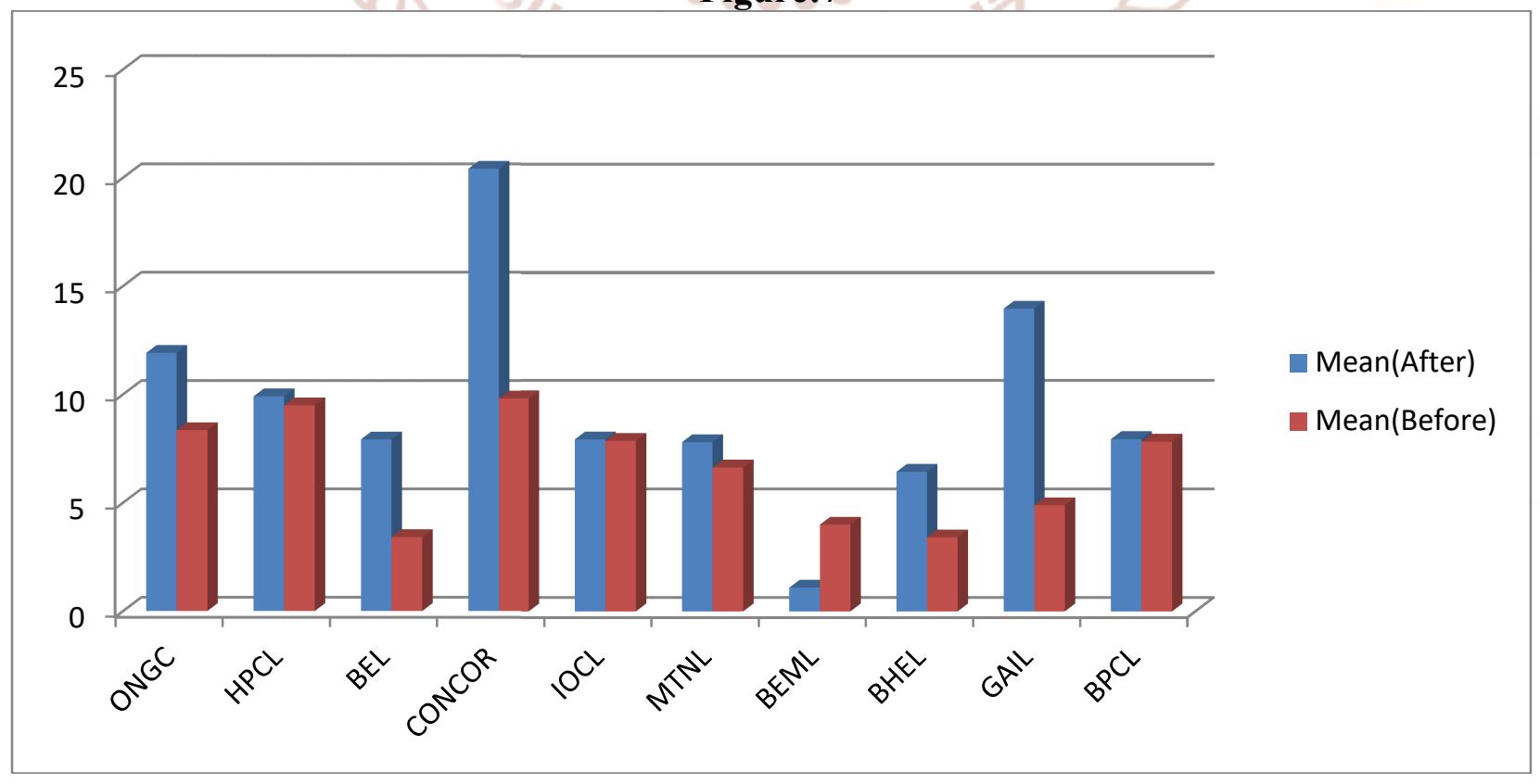


From the above Table 7 we can analyze the results of consolidated impact of disinvestment on the measure under consideration. It analyzes the significant difference between the two groups viz. pre and post disinvestment periods. For this purpose we applied two pair sample T-test at five prevent level of significance. It can be concluded with the help of Table 7 that in case of ONGC, BPCL, CONCOR, IOCL, BEML, BHEL,G AIL and BPCL, significant difference is found and Null Hypothesis is rejected for these cases at five percent level of significance while rest two units viz. BEL and MTNL has not any significant difference in pre and post disinvestment period. Finally, we can conclude that the Dividend Payout Ratio is found sound in all the units under the scope of our study except BEL, MTNL and BHEL, while on the contrary others showed a positive distribution of dividend in post disinvestment period.

\section{REFERENCES}

1) A Boardman, A. V. (1989, April). Ownership and performance in competitive environments: a comparison of theperformance of private, mixed, and state-owned enterprises. $J$ Law Econ, XXXII(1), 1-33.

2) Abelson, P. (2003, March). Public Enterprise Disinvestement: Australian case studies. Econ Record, ABI/INFORM Global, 79(244), 152-154.

3) Akintayo, D. (2010). A conceptual study of privatization of public enterprises and industrial relation practices in amixed recessionary economy. International Business Economic Research, $I X(12), 141-147$.

4) B Hamid, C.-C. C. (2006). Environmental policy, comparative advantage, and welfare for a developing economy.Environ Dev Econ, 11(5), 559-568.

5) BG Katz, J. O. (1995, August). Designing an optimal privatization plan for restructuring firms and industries intransition. J Cornp Econ, XXI(1), $1-28$.

6) Bradbury, ME. (1999). Government ownership and financial performance in a competitive environment: evidencefrom the corporatization of the New Zealand government computing services. ABI/INFORM Global, Singapore,XVI(1), pp. 157172

7) Brittan, S. (1986, March). Privatization: a comment on key and Thompson. Econ J,
XCVI(381), 33-38. Carino, L. (2008). Towards a strong republic: enhancing the accountability of the philippine state. PublicAdminisatration Quarterly, 32(1), pp. 59-92.

8) Chris, E. (2010). Public sector unions and the rising costs of employee compensation. Cato J, $X X X(1), 87-115$.

9) Aggarwal, G.C. (1976), "Public Sector Steel Industry in India", ChaitanyaPublishing House, Allahabad.

10) Aggarwal, M.D. \&Mathur, B.L. (1986), "Public Enterprises in India",Ramesh Book Depot, Jaipur.

11) Aggarwal, R.C. (1961), "State Enterprises in India", Chaitanya PublishingHouse, Allahabad.

12) Bairath, S. "Management of Working Public Enterprises, PointsPublications, Jaipur, p. 230.

13) Banerji (1970), "Handbook of Information on Public Enterprises.[7] Bhatia, B.S. and Batra, G.S. (1995), "Management of Public Enterprises,Performance and Policy Perspectives", Deep and Deep Publications, RajouriGarden, New Delhi.

14) Chatterjee, N.N. (1978), "Performance Appraisal Systems in PublicEnterprises", Standing Conference of Public Enterprise, New Delhi.

15) Gadhok, D.N. (1980), "Accountability of Public Enterprise",Sterling Publisher Pvt. Ltd., New Delhi.

16) Gupta, S.P. (2000), "Statistical Methods" S. Chand \& Sons, NewDelhi.

17) Guru, D.D. and Ahsan, Q. (1987), "Public Enterprise", AmarParkashan, New Delhi.

18) Hanson, A.H. (1995), "Public Enterprises and EconomicDevelopment", Routledge and Kegan Paul Ltd., London.

19) Murdeshwar, A.K., Administrative Problems Relating toNationalisation with Special Reference to Indian State Enterprises, PopularBool Depot, Bombay, 1957.

20) Naib,Sudhir.(2004)," Disinvestment in India Policies,Procedure andProgress" Sage Publication, New Delhi.

21) NarainLuxmi (1986), "Principles and Practice of Public EnterpriseManagement", S. Chand and Company Ltd., Ram Nagar, New Delhi. 
22) Parkash, J. (2002), "Public Enterprises in India", Thinker's Library,Allahabad.

23) Raghavan, S.N. (1994), "Public Sector in India ChangingPerspectives", Asian Institute of Transport Development, Sri AurbindoMarg, New Delhi.

24) Ramanadham, V.V. (1987), Privatization in Developing Countries,Routledge and Kegan Paul Ltd., London.

25) Kiran Kumar, Chetan Kumar," Disinvestment Policy in India: Progress and Challenges" INDIAN JOURNAL OF APPLIED RESEARCH, Volume : 3, Issue : 8 ,Aug 2013

26) Samuel Paul, "Privatisation and the Public Sector", Finance and Development, December, 1985.

27) Administrative Reforms Commission (ARC) Report of the Study on Public Sector Undertakings.

28) Majumdar S, "Why disinvestment has not attracted Fdi\Business Lines, June 11,2002.

29) DattRuddar and KpmSundram, "Indian Economy", S. Chand and Company Ltd., New Delhi.

30) AlokRoy,"Article on PSU disinvestment: Endemicproblems", electronic publication, 2003.
31) R Nagaraj,"Disinvestment and Privatisation in IndiaAssessment and Options".

32) PradipBaijal,"Disinvestment in India, I lose and yougain".

33) Disinvestment Commission Report, 1999

34) Economic Survey, 1991-2008

35) T. N. Srinivasan,"Indian Economic Reforms: A Stocktaking",2010.

36) Mohan Joshi,"High lights their national building potential",Vajpayee Bemoans PSUs decay. Budget, special, 2000.

37) Public sector enterprise survey,"Disinvestmentprivatisation",Vol. 1, 2005-06.

38) Planning Commssion Report, 2003

39) R. Nagaraj,"Public Sector performance since 1950", A freshlook".

40) Public enterprise Survey Report 1996-1997,20022004.Vol-1.

41) DeveshKapur, Ravi Ramamurti,"PRIVATIZATION INIndia: THE IMPERATIVES AND CONSEQUENCES OFGRADUALISM", 2002.

42) World Economic Forum: India ECONOMIC SUMMIT,2009 